ción y desarrollo de los sistemas econó micos merecen ser destacados por la atractiva y completa sínesis realizada.

Se podrian hacer, sin embargo, dos pequeñas apreciaciones a la obra. En primer lugar, el análisis de algunos bloques regionales peca de cierto ahistoricismo que le convierte en un texto muy coyuntural. El ejemplo más claro es el capítulo dedicado a la economía estadounidense.

En segundo lugar, conviene hacer una observación sobre la selección de variables utilizadas en la descripción de las economias latinoamericanas. Si bien la selección efectuada corrige el frecuente error de olvidar los datos sobre algunos de los principales desequilibrios macroeconómicos, llama la atención que no incluya el porcentaje de población por debajo del umbral de pobreza que es una variable inevitable para la comprensión de la realidad latinoamericana.

En resumen, es una obra que cumple los objetivos para los que se ha claborado. Ofrece una perspectiva completa y global sobre los principales probtemas de la economía internacional, sin omisiones importantes.

Pedro Caldentey del Pozo

\section{AMERRCA LATINA}

COMISIÓN ECONÓMICA PARA AMERICA LATINA Y EL CARIBE (CEPAL). (1990), Transformación productiva con equidad.

CEPAL. (1991), El desarrollo sustentable: transformación productiva, equidad y medio ambiente.

CEPAL-UNESCO. (1992), Educacióny conocimiento: eje de la transformación productiva con equidad.

Edita Naciones Unidas, Comisión económica para América Latina y el Caribe, Santiago de Chile.

Los tres documentos que se reseñan a continuación consituyen la elaboración completa del marco teórico del modelo de desarrollo que presenta la CEPAL para América Latina y el Caribe en este final de siglo y de cara al comienzo del próximo.

Tras el relativo fracaso del modelo cepalino de sustiución de importaciones en las decadas de los sesenu y setenta y tras los malos resultados de la aplicación de las políticas de ajuste estructural durante los ochenta, la CEPAL hace una nueva propuesta.

Duranle los últimos años, el Banco Mundial yel FMI han ligado la concesión de créditos y ayudas a la aplicactón de unos planes de ajuste estructural que han tenido consecuencias negativas para los sectores más desfavorecidos y mayoriarios de los parses de América Latina. En 
este entorno, la CEPAL, cuya concepción del desarrollo es notablemente distinta que la de los organismos citados, ha lanzado su propuesta de $n^{\circ}$ ans fortunto productiva con equidad.

El documento publicado en 1990, iras una síntesis inicial, parte del análisis de las economías de América Latina y el Caribe después de la llamada década perdida. Obviamente, el análisis wace especial hincapié en los años ochenta que son considerados como un punto de inflexión entre el parón de desarrollo precedente en América Latina y el Caribe, y una fase, aún no completamente perfilada pero sin duda diferente, que marcará el desarrollo futuro de la región. El documento hace una síntesis del periodo basada en los siguientes fenómenos: la pérdida de dimamismo de las conomálas latinoamericanas; la imposibilidad de controlar los grandes desequilibrios macroeconómicos a partir de las politicas de ajuste; el carńcter regresivode dicho ajuste y sus efectos en las sociedades latinoamericanas; el debilitamiento del sector público y la caída de la inversión.

La América Latina resultante de esta evolución reciente se plantea la necesidad de retomar el camino hacia el desarollo y ello precisa la realización inmediata de determinadas transformaciones estructurates que permitan la recuperación y posterior crecimiento de las economías. Sin embargo, el deterioro social generado por el ajuste estructural exige también acciones inmediatas. La mejora de las condiciones de vida y trabajo de los latinoamericanos es, según la CEPAL, un requisito indispensable para el éxito de las transformaciones productivas. Por ello, éstas deben ir acompañadas de un marco de creciente equidad social.

El objetivo básico de la propuesta es fortalecer to que en el documento se denomina comperitividad auténtica, que es aquella basada en la incorporación del progreso técnico y no en la reducción de los salarios reales. Pan ello, las políicas de desarrollo deben garantizar la aricici. lación productiva entre todos los sectores, la mejora de la inserción internacional de los paises latinoamericanos y la interacción entre agentes privados y públicos.

El cumplimiento de estos objetivos se verá condicionado por determinados factores. Unos extemos: el grado de apertura de las economas, el exceso de endeudamiento y el acceso a tecnología y conocimientos. $Y$ otros internos: el control de los desequilibrios macroeconómicos, el rinanciamiento de las políticas de desarrollo y la cohesión social en como a las políticas.

Para CEPAL las claves del éxito de esta propuesta son la incorporación del progreso técnico, la integración sectorial de las economías basada en la industrialización, el uso adecuado de los recursos naturales, y un crecimiento económico sostenido que garantice la equidad social.

A partir de estos supuestos CEPAL sugiere determinadas politicas: fiscal, comercial y cambiaria, tecnológica, de formación de recursos humanos, de crea-

\section{RFS}


ción de empresas, indusirial, etc. De entre ellas cabe destacar la sugerencia de una apertura comercial gradual y selectiva frente a las politicas de liberalización exirema sugeridas desde otros organismos internacionales.

En cuanto al papel del sector público, el documento elude la polémica frontal pero se decanta, siguiendo la tradición de CEPAL, por la presencia activa del Estadoen la dirección de la economía y como catalizador de la misma. Sugiere su readecuación y no la reducción de su actividad.

Los dos documentos siguientes adaptan la transformación productiva con equidad a dos conceptos sumamente importantes y que no habian sido resaltados suficientemente en el documento de 1990: el desarrollo sustentable sostenible y la educación.

Si en el primer trabajo, la Cepal hacia referencias a la necesidad de que el desarrollo fuera respetuoso con el medio ambiente y los recursos naturales, este documento precisa y elabora más la relación entre desarrollo sostenible y crecimiento económico. La CEPAL insiste en la conveniencia de elaborar políticas coherentes, a nivel regional y con la participación de los organismos internacionales para garantizar los resultados. La idea subyacente es que un problema global no se puede abordar individualmente.

El documento de 1992 corrige una omisión de la primera elaboración del modelo. Aunque entre las políticas de desarrollo se incluía la formación de recursos humanos, no se le otorgaba un papel principal. El tíulodel trabajo, ${ }^{6}$ Educación y conociniento: eje de la transformación productiva con equidad", muesra la imporancia de la educación en la jerarqua de políticas para el desarollo de la CEPAL.

En conclusión, estos tres trabajos muestran el nuevo discursode la CEPAL. un discurso de modemización de las economías pero sensible a las necesidades sociales de la región y con vocación de incluir en el desarrollo a las mayorias. $\Psi$ un discurso responsable con el medio ambiente $y$ con el concepto de sostenibilidad.

La CEPAL plantea con el modelo de transformación productiva con equidad un modelo de desarrollo notablemente distinto a los planes de ajuste estructural que actualmente proponen el Banco Mundial y el FMl. Su planteamiento parece más apropiado para la región que los citados planes de ajuste. Sin embargo, la formulación del modelo es demasiado general en algunos aspectos y su aplicación parece extremadamente compleja. Aunque obviamente la propuesta es un marco global donde cada país debe plantear sus prioridades (de acuerdo a sus propias especificidades) la ambición del modelo plantea ciertos riesgos. La transformación productiva con equidad proporciona un modelo de desarrollo cuyo éxito va a estar muy condicionado por factores extemos y que dependerá, tal y como la CEPAL afirma, del grado de participación social que suscite.

Pedro Caldentey del Pozo 